\title{
Physical Activity Reduces Prostate Carcinogenesis in a Transgenic Model
}

\author{
Karyn A. Esser ${ }^{1}{ }^{\star}$, Clifford E. Harpole ${ }^{1}$, Gail S. Prins ${ }^{2}$, and Alan M. Diamond ${ }^{3}$ \\ ${ }^{1}$ Department of Physiology, University of Kentucky, Lexington, Kentucky \\ 2 Department of Urology at the University of Illinois at Chicago, Chicago, Illinois \\ ${ }^{3}$ Department of Pathology at the University of Illinois at Chicago, Chicago, Illinois
}

\section{Abstract}

BACKGROUND—Several epidemiological studies have reported an inverse association between physical activity and the risk of prostate cancer. To date, there are few animal studies looking at physical activity and cancer incidence, although the results are consistent with the epidemiological evidence. In general, as exercise intensity increased in the rats/mice, the likelihood that physical activity inhibited carcinogenesis increased.

METHODS-The present study used voluntary wheel running with C3(1)Tag mice that are predisposed to prostate cancer due to the directed expression of SV40 oncogenes. After 10 weeks, the prostates were collected from run and non-run mice and histopathology performed for the presence or absence of low grade or high grade PINS.

RESULTS-We found that for those mice that ran $>5 \mathrm{Km} /$ group, $83 \%$ of the dorsolateral prostates were classified as within normal levels vs. $43 \%$ for the $<5 \mathrm{~km} /$ day group $(\mathrm{p}=0.16)$. In addition, there was a relationship between average distance run and pathologic progression to high-grade PIN and local invasion, considered to be an early event in the formation of prostate adenocarcinoma. Forty three percent of dorsalateral prostates from mice that ran less than $5 \mathrm{~km} /$ day were classified with advanced pathology as compared to none (0) in mice that ran more than $5.0 \mathrm{~km} / \mathrm{day}(\mathrm{p}=0.05)$.

CONCLUSIONS-The results presented herein indicate that prostatic cancer progression is likely delayed or diminished by wheel running activity in a dose dependent manner in transgenic mice. These findings provide further evidence that exercise acts to decrease the progression of prostate cancer and they establish a transgenic animal model for future studies to define mechanism(s).

\section{Keywords}

exercise; voluntary running; cancer

\section{INTRODUCTION}

With the worldwide increase in life expectancy, the leading causes of death have shifted dramatically from infectious/communicable diseases in the young to cardiovascular disease and cancer in the old. Studies are increasingly demonstrating that life style choices play a prominent role in both the quality and length of life. For example, a recent study from 11 European countries, Healthy Ageing: A Longitudinal Study in Europe (HALE) analyzed 10year mortality from coronary heart disease, cardiovascular disease, and cancer as a function of

*Correspondence to: Karyn A. Esser, PhD, Department of Physiology, College of Medicine, University of Kentucky, 800 Rose Street, UKMC MS567, Lexington, KY 40536. kaesse2@uky.edu. 
the Mediterranean diet, being physically active, moderate alcohol consumption, and nonsmoking in a population of 70- to 90 -year olds. Adherence to this low-risk pattern was associated with a decreased population attributable risk of 50\% from cancer [1]. However, the mechanism by which these life-style choices contribute to increased longevity are only beginning to be understood. Several studies have reported an inverse association between physical activity and the risk of prostate cancer with recent data reporting associations between strenuous physical exercise and prostate cancer risk [2-5].

To date, there are few animal studies looking at physical activity and cancer incidence, although the results are consistent with the epidemiological evidence. For example, two studies have reported that voluntary running decreases carcinogen-induced colon tumor incidence in rats [6,7]. Similar results were reported for moderate exercise with a rotating-drum treadmill [8] and in a transplant model where murine lymphoid leukemia cells transplanted into exercisetrained mice were shown to be growth-inhibited by $50 \%$ in those mice that continued to exercise after transplantation compared to those that were sedentary [9]. A recent study also showed that physically active rats injected with carcinogen exhibited less mammary tumor incidence and multiplicity when compared to sedentary controls [10]. In general, as exercise intensity increased in the rats/mice, the likelihood that physical activity inhibited carcinogenesis increased [11,12]. Exercise intensity, in this context, refers to the relative rate of work for the rodent/human relative to their maximum capacity. This link between intensity and cancer outcomes is quite different than the link between exercise and weight loss, for example. In terms of modulation of body weight, the predominant factor is in the total amount of work done independent of the work rate [13]. With cancer prevention, work rate/intensity, seems to be critical and this consideration is useful when thinking about potential mechanisms [11]. It is important to note that the effect of exercise on cancer risk is independent of its influence on body weight [14] demonstrating that the studies of physical activity on cancer risk need to be performed in the absence of dietary modifications.

In order to establish an animal model to investigate the effects of physical activity on prostate cancer development, the present study used C3(1)Tag mice that are predisposed to prostate cancer due to the directed expression of SV40 oncogenes to that organ $[15,16]$ combined with voluntary exercise. Each mouse was placed in a cage with a running wheel that was connected to a computer for online data collection on wheel running behavior. This aspect of the design was important as physical activity tends to be over-simplified in many animal studies with little to no quantification of data with respect to variables such as intensity, duration, and frequency of running. The ability to collect individual mouse running data allowed for post hoc analyses taking advantage of the variation in running activity between mice. This type of analysis offers the unique potential to provide insight into mechanisms, as well as to provide the data to address issues of dose response of exercise and cancer prevention. Voluntary wheel running is an established model of endurance exercise for rodents, with mice showing both cardiac and skeletal muscle adaptations after 2-4 weeks of wheel running [17]. The model has been extensively characterized and, when given access to a running wheel, most mouse strains will run from 5 to $8 \mathrm{~km}$ a night (variation depending on strain, sex, and age). The results presented herein clearly establish an inverse association between the amount of physical activity performed by an individual mouse and the development of prostatic intraepithelial neoplasia (PIN) associated with prostate cancer development.

\section{MATERIALS AND METHODS}

Twenty-nine male 10-week-old C3(1)Tag mice were housed at an animal care facility at the Medical Center of the University of Kentucky that is accredited by the American Association for Accreditation of Laboratory Animal Care. The C3(1)Tag mice were generated by mating homozygous C3(1)Tag males [13,14] with wild-type FVB/N females and heterozygote males 
on the FVB/N background were used in this study. The mice were housed in a 12:12 hr light/ dark cycle and with free access to food (2918 Teklad Global 18\% Protein Rodent Maintenance Diet) and water. The animal protocol was approved by the Institutional Animal Care and Use Committee at the University of Kentucky.

The C3(1)Tag male mice were divided into two groups: 9 were placed in the control nonrunning group and 20 in the running group. All mice were individually housed in standard sized polycarbonate boxes with (running group) or without (control non-running group) a running wheel. Out of the nine mice in the non-run group, eight mice lived through the duration of the study with one mouse dying after 6 weeks. All 20 wheel running mice lived for the duration of the study. The wheel running activity for each mouse was monitored $24 \mathrm{hr} /$ day and 7 days/week using ClockLab software (Actimetrics, Inc.) as reported previously [18]. The results from ClockLab were entered into an Excel spreadsheet for computation of daily running distance, average running speed and duration (time). Body weights for each mouse were determined at least three times per week. Mice were maintained in the run and non-run groups for 10 weeks. At 20 weeks of age, the mice were euthanized and the prostates collected for pathologic evaluation. The age at the start and end of the access to running was chosen since previous work with this model in our laboratories revealed a high percentage of tissues as histologically normal at 10 weeks with detectable carcinogenesis underway by 20 weeks of age $[13,16]$. We sought to determine if this progression could be affected by introduction of physical activity.

\section{Histopathology}

The entire prostatic complex was dissected from the urethral and reproductive tract connections and fixed en masse overnight in 10\% buffered formalin (Fisher Diagnostics, Middletown, VA). Each specimen was coded to avoid observer bias in processing and pathological diagnosis. The fixed specimens were dehydrated in increasing concentrations of ethanol and paraffin embedded. The prostatic complex was sectioned along the longitudinal axis at three levels in the paraffin block to provide multiple sections per prostate followed by routine staining with hematoxylin and eosin (H\&E). The sections were scored in a blinded manner as previously described [19]. Observations were made on the presence and degree of epithelial hyperplasia and the presence of nuclear atypia in the separate ventral and dorsolateral lobe regions. Samples with no nuclear atypia were classified as "within normal limits" (WNL) whereas specimens with nuclear atypia were further classified as low-grade prostatic intraepithelial neoplasia (LGPIN) or high grade PIN (HGPIN) lesions according to accepted criteria of the College of American Pathologists and further characterized for mouse models [20]. Evaluation was made of basement membrane breakdown and local microinvasion and was positively scored only when basement membrane breakdown and epithelial cells within the adjacent stroma were observed in the immediate vicinity of PIN lesions which would suggest appropriate progression. The degree of neoplasia for each lobe was characterized as focal or extensive using $>25 \%$ area as the cut-off between the two categorizations. The diagnoses were recorded for the dorsolateral and ventral prostates separately. After the diagnoses were recorded, the code for the group was broken and the data tabulated for analysis. Differences between groups for body weight, running distance, speed, and time were tested using a two-tailed $t$-test and significance was considered at $P \leq 0.05$. To statistically test for significance between the categorical data, presence of pathology versus running distance/day, we used the Fisher's Exact Test with categories of different running distances/day versus pathology.

\section{RESULTS}

C3(1)Tag mice ran an average of $4.03 \pm 0.39 \mathrm{~km} / \mathrm{day}$, but the running distance was variable across the individual mice with the range in average distances from lowest to highest being 
$1.26-7.72 \mathrm{~km} /$ day (Table I). The average running speed on the wheels was $0.72 \pm 0.05 \mathrm{~km} / \mathrm{hr}$. In general, the running speed and distance for these C3(1)Tag mice was within the range of speed and distances reported for male mice of different strains [21]. We also monitored the body weight of both the non-running and running mice and there was no difference found between the groups and all mice increased body weight (from $\approx 24$ to $30 \mathrm{~g}$ ) throughout the length of the study (Fig. 1). These findings are consistent with our observation that the mice did not exhibit any significant signs of overt disease for the full length of the study.

Dorsolateral and ventral prostates were removed from 20-week-old animals following 10 weeks of access to the running wheel or continued sedentary housing (controls). Prostate tissues were coded as to be blinded by the examiner and analyzed for the presence, degree and progression of PIN, using classifications of normal, low grade, high grade, focal, extensive, microinvasion, and adenocarcinoma, with representative examples of histopathology presented in Figure 2. Initial examination of the data from the mice in this study did not reveal any apparent differences in histopathology grading between those mice animals housed in standard cages, representing the non-running group, and those provided access to the running.

Examination of the running data presented in Table I for animals given access to the running wheel indicated that there was a significant variation in average distance run/day among all mice. If we grouped all the running mice together and analyzed the pathology to that seen in the non-runners there was no statistical difference between the frequency of WNL between groups for the dorsolateral prostate $(P=0.18: \mathrm{n}=27)$ or the ventral prostate $(P=0.35: \mathrm{n}=27)$. However, since there was significant variability in the running behavior among the mice we performed post hoc analysis using Fisher's Exact Test for testing categorical data of smaller sample sizes. Using this approach we found that if we categorized the running mice into two groups, those that ran less than $5 \mathrm{~km} /$ day versus those that ran more than $5 \mathrm{~km} / \mathrm{day}$ we did detect significant differences between running behavior and pathology. This subgroup of running mice $(\mathrm{n}=6)$ consistently ran significantly farther per day $(\approx 5.9 \mathrm{~km} /$ day $)$ compared to the average running distance for the rest of the runners $[3.31 \mathrm{~km} / \mathrm{day}(P<0.001)]$. When we analyze prostate pathology by running groups $(>5 \mathrm{~km} v \mathrm{vs} .<5 \mathrm{~km})$ we did see a trend for a higher percentage of dorsolateral prostates that exhibit a normal phenotype in those mice that ran $>5$ $\mathrm{km} /$ day (Fig. 3). For those mice that ran $>5 \mathrm{~km} /$ day, $83 \%$ of the dorsolateral prostates were classified as WNL versus $43 \%$ for the $<5 \mathrm{~km} /$ day group $(P=0.16)$. These results are presented in Figure 3 with the same trend apparent for the ventral prostate but the effect was less dramatic. Upon further analysis of the running data for these two groups of mice, we found a statistical difference between the average running speed of the mice that ran $>5 \mathrm{~km} /$ day $(0.87 \mathrm{~km} / \mathrm{hr})$ when compared to the mice that ran $<5 \mathrm{~km} /$ day $(0.7 \mathrm{~km} / \mathrm{hr}: P=0.01)$. The mice in the $>5 \mathrm{~km}$ group also ran for a longer duration per day, $6.7 \mathrm{hr} /$ day versus $4.5 \mathrm{hr}$ /day for the mice that ran $<5 \mathrm{~km} /$ day. The trend for differences in prostate pathology in mice that exhibit greater average running speed and duration support the work of others that link intensity of exercise with inhibition of cancer progression, as reviewed in the Introduction Section.

The data were next assessed for a relationship between average distance run and pathologic progression to high-grade PIN and local invasion, considered to be an early event in the formation of prostate adenocarcinoma. As noted in the methods, local invasion was strictly characterized when basement membrane breakdown was observed in the presence of highgrade PIN. Data for the percentage of prostates with high-grade PIN without or with associated local invasion are Figure 4 and show a significant effect in the dorsolateral prostate with $43 \%$ of the prostates derived from presented in animal that ran less than the $5 \mathrm{~km} /$ day cutoff being classified with advanced pathology as compared to none in animals that ran more than $5.0 \mathrm{~km} /$ day $(P=0.05)$. This effect of running was also apparent as a trend in the in the ventral prostate, where there was a $65 \%$ reduction in advanced pathology in ventral prostates derived from mice 
that ran $>5.0 \mathrm{~km} /$ day as compared to those that ran less $(P=0.18)$, although the trend did not reach statistical significance.

\section{DISCUSSION}

The results of this study indicate that prostatic cancer progression is likely delayed or diminished by increased wheel running in transgenic C3(1)Tag mice. We found that mice that ran greater than $5 \mathrm{~km} /$ day were found to exhibit a lower frequency of high grade PIN pathology. It is important to note that this observation was made post hoc following a more detailed analysis of the results. If we analyzed all running data vs. pathology there was no statistically difference between groups. This suggests that there is a threshold volume of running activity required to provide the potentially protective effects of exercise on prostate cancer progression. Due to the smaller sample size in this study we were not able to delineate any potential intermediate level of protection against prostatic lesions for mice running less than $5 \mathrm{~km} /$ day. We do believe that the protective effects of running $>5 \mathrm{~km} /$ day are likely the result of humoral effects on the prostate resulting from the physical activity and not indirect effects from the effects of running on body composition. Specifically we found no differences in body weight among the groups of runners or between the runners and non-runners. These observations are consistent with epidemiological studies that suggest that physical activity acts independent of body weight in the prevention or delayed progression of prostate cancer [2-5]. These data also provide important evidence for an appropriate animal model and methodological approach to study the consequential benefits of physical activity on prostate cancer incidence, while revealing little about the mechanisms of protection. Future studies will utilize larger animal numbers to assess whether more moderate exercise is beneficial as well, and will also determine whether the protection offered by exercise in C3(1)Tag mouse can be generalized to different strains. In addition, the determination of effects of physical activity on immune function and signaling pathways relevant to carcinogenesis in the prostate will need to be conducted to start to understand the mechanisms involved in the reduction of cancer incidence, which perhaps could be generalized to other organs as well. Increased physical activity is an attractive approach to reduce prostate cancer risk as it involves a life style change that is likely to be embraced by men at-risk more readily that alternative chemopreventive strategies. It is anticipated that the use of the animal model presented in this manuscript will lead to new scientific insight that will eventually help to formulate hypotheses and generate biomarkers of efficacy in human intervention studies.

\section{Acknowledgments}

We would like to thank Dr. Arnold Stromberg for assistance with statistical analysis and Ms. Lynn Birch for technical assistance. This work was supported by a grant from the UK Markey Cancer Center to KAE and NIH grant R01CA101053 to AMD and GSP.

Grant sponsor: UK Markey Cancer Center; Grant sponsor: NIH; Grant number: R01CA101053.

\section{References}

1. Knoops KT, de Groot LC, Kromhout D, Perrin AE, Moreiras-Varela O, Menotti A, van Staveren WA. Mediterranean diet, lifestyle factors, and 10-year mortality in elderly European men and women: The HALE project. JAMA 2004;292(12):1433-1439. [PubMed: 15383513]

2. Friedenreich CM, McGregor SE, Courneya KS, Angyalfi SJ, Elliott FG. Case-control study of lifetime total physical activity and prostate cancer risk. Am J Epidemiol 2004;159(8):740-749. [PubMed: 15051583]

3. Darlington GA, Kreiger N, Lightfoot N, Purdham J, Sass-Kortsak A. Prostate cancer risk and diet, recreational physical activity and cigarette smoking. Chronic Dis Can 2007;27(4):145-153. [PubMed: 17623560] 
4. Gallus S, Foschi R, Talamini R, Altieri A, Negri E, Franceschi S, Montella M, Dal Maso L, Ramazzotti $\mathrm{V}, \mathrm{La}$ Vecchia C. Risk factors for prostate cancer in men aged less than 60 years: A case-control study from Italy. Urology 2007;70(6):1121-1126. [PubMed: 18158031]

5. Krishnadasan A, Kennedy N, Zhao Y, Morgenstern H, Ritz B. Nested case-control study of occupational physical activity and prostate cancer among workers using a job exposure matrix. Cancer Causes Control 2008;19(1):107-114. [PubMed: 18064535]

6. Andrianopoulos G, Nelson RL, Bombeck CT, Souza G. The influence of physical activity in 1,2 dimethylhydrazine induced colon carcinogenesis in the rat. Anticancer Res 1987;7(4B):849-852. [PubMed: 3674772]

7. Reddy BS, Sugie S, Lowenfels A. Effect of voluntary exercise on azoxymethane-induced colon carcinogenesis in male F344 rats. Cancer Res 1988;48(24 Pt 1):7079-7081. [PubMed: 3191484]

8. Lane HW, Teer P, Keith RE, White MT, Strahan S. Reduced energy intake and moderate exercise reduce mammary tumor incidence in virgin female BALB/c mice treated with 7,12-dimethylbenz(a) anthracene. J Nutr 1991;121(11):1883-1888. [PubMed: 1941196]

9. Radak Z, Gaal D, Taylor AW, Kaneko T, Tahara S, Nakamoto H, Goto S. Attenuation of the development of murine solid leukemia tumor by physical exercise. Antioxid Redox Signal 2002;4(1): 213-219. [PubMed: 11970855]

10. Zhu Z, Jiang W, Sells JL, Neil ES, McGinley JN, Thompson HJ. Effect of nonmotorized wheel running on mammary carcinogenesis: Circulating biomarkers, cellular processes, and molecular mechanisms in rats. Cancer Epidemiol Biomarkers Prev 2008;17(8):1920-1929. [PubMed: 18708381]

11. Thompson HJ. Effect of exercise intensity and duration on the induction of mammary carcinogenesis. Cancer Res 1994;54(7 Suppl):1960s-1963s. [PubMed: 8137320]

12. Thompson HJ. Effects of physical activity and exercise on experimentally-induced mammary carcinogenesis. Breast Cancer Res Treat 1997;46(2-3):135-141. [PubMed: 9478269]

13. Ballor DL, McCarthy JP, Wilterdink EJ. Exercise intensity does not affect the composition of dietand exercise-induced body mass loss. Am J Clin Nutr 1990;51(2):142-146. [PubMed: 2305700]

14. Rockhill B, Willett WC, Hunter DJ, Manson JE, Hankinson SE, Colditz GA. A prospective study of recreational physical activity and breast cancer risk. Arch Intern Med 1999;159(19):2290-2296. [PubMed: 10547168]

15. Shibata MA, Jorcyk CL, Liu ML, Yoshidome K, Gold LG, Green JE. The C3(1)/SV40 T antigen transgenic mouse model of prostate and mammary cancer. Toxicol Pathol 1998;26(1):177-182. [PubMed: 9502400]

16. Shibata MA, Ward JM, Devor DE, Liu ML, Green JE. Progression of prostatic intraepithelial neoplasia to invasive carcinoma in C3(1)/SV40 large T antigen transgenic mice: Histopathological and molecular biological alterations. Cancer Res 1996;56(21):4894-4903. [PubMed: 8895741]

17. Waters RE, Rotevatn S, Li P, Annex BH, Yan Z. Voluntary running induces fiber type-specific angiogenesis in mouse skeletal muscle. Am J Physiol Cell Physiol 2004;287(5):C1342-C1348. [PubMed: 15253894]

18. Esser KA, Su W, Matveev S, Wong V, Zeng L, McCarthy JJ, Smart EJ, Guo Z, Gong MC. Voluntary wheel running ameliorates vascular smooth muscle hyper-contractility in type 2 diabetic $\mathrm{db} / \mathrm{db}$ mice. Appl Physiol Nutr Metab 2007;32(4):711-720. [PubMed: 17622286]

19. Diwadkar-Navsariwala V, Prins GS, Swanson SM, Birch LA, Ray VH, Hedayat S, Lantvit DL, Diamond AM. Selenoprotein deficiency accelerates prostate carcinogenesis in a transgenic model. Proc Natl Acad Sci USA 2006;103:8179-8184. [PubMed: 16690748]

20. Shappell SB, Thomas GV, Roberts RL, Herbert R, Ittmann MM, Rubin MA, Humphrey PA, Sundberg JP, Rozengurt N, Barrios R, Ward JM, Cardiff RD. Prostate pathology of genetically engineered mice: Definitions and classification. The consensus report from the bar harbor meeting of the mouse models of human cancer consortium prostate pathology committee. Cancer Res 2004;64:2270-2305. [PubMed: 15026373]

21. Lerman I, Harrison BC, Freeman K, Hewett TE, Allen DL, Robbins J, Leinwand LA. Genetic variability in forced and voluntary endurance exercise performance in seven inbred mouse strains. $\mathrm{J}$ Appl Physiol 2002;92(6):2245-2255. [PubMed: 12015333] 


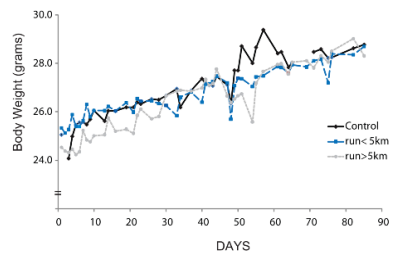

Fig. 1.

Average body weights for C3(1)Tag mice in the non-run, run $<5 \mathrm{~km} /$ day and run $>5 \mathrm{~km} /$ day groups over the duration of the study. Mice were individually housed and body weight for each mouse was determined every 3rd day. All mice continued to gain weight over the course of the study and we did not detect any significant differences in the body weights across all three groups. 


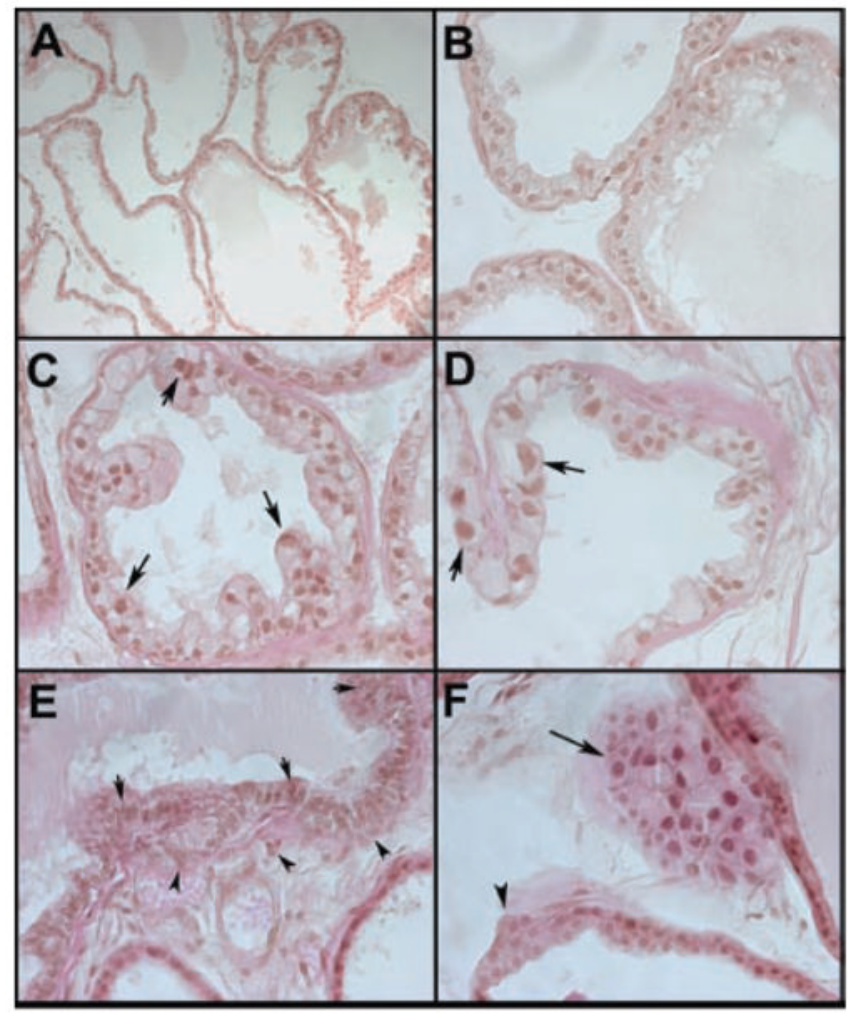

Fig. 2.

Ventral prostate histology in C3(1) Tag mice at 20 weeks of age. A, B: Low power and higher power view of a ventral lobe classified as "with in normal limits" or WNL. C: Acini within a ventral lobe exhibiting low-to-medium grade PIN as characterized by enlarged nuclei (arrows), cell piling and large intracellular vacuoles. D: Prominent distortion and enlargement of nuclei (arrows) as well as varied nuclear size across the acini is characteristic of high-grade PIN lesions. E: High grade PIN (arrows) with evidence of epithelial cell microinvasion (arrowheads) across the basement membrane. F: Focal microinvasion of epithelial cells with variable sized nuclei (arrow) as well as evidence of basement membrane breakdown (arrow head) in an adjacent acini. 




Fig. 3.

Percent of Tag mice with normal dorsal or ventral prostates. Mice were divided into two groups with those running $>5 \mathrm{~km} /$ day versus those running $<5 \mathrm{~km} /$ day. Fisher's Exact was run with significance set at $P \leq 0.05$. There was a trend for greater normal dorsal prostates in the mice that ran $>5 \mathrm{~km} /$ day but $P=0.16$. There was no difference in the percent normal ventral prostates between the groups. 
Dorsal Prostate

- Ventral Prostate

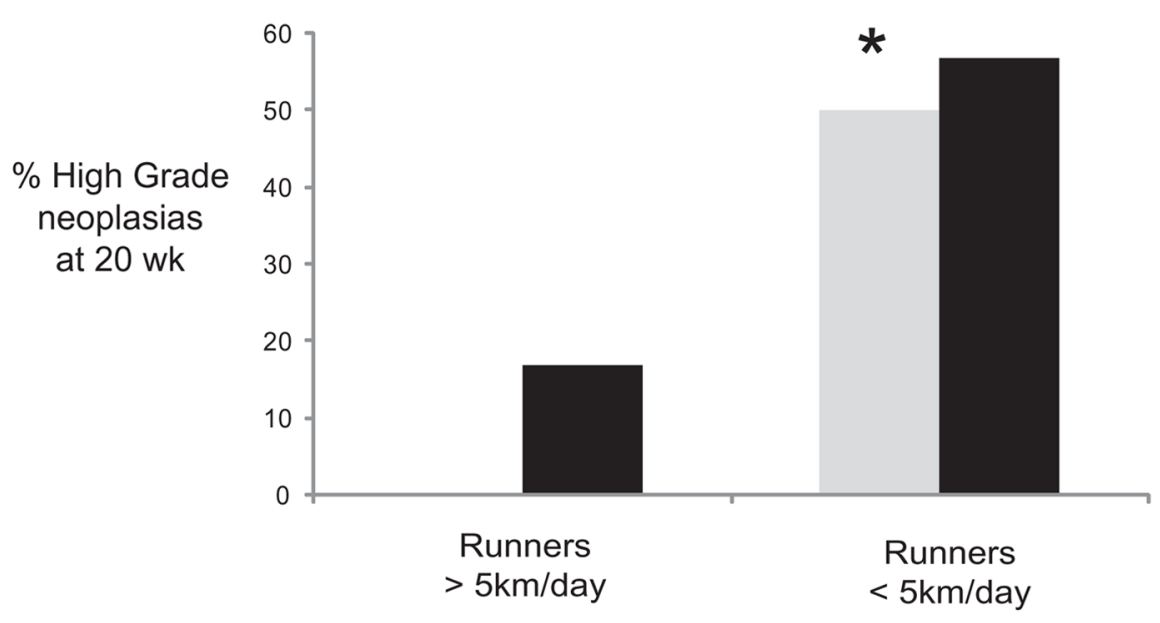

Fig. 4.

Percent of Tag mice that exhibited high grade (HG) pins in the dorsal or ventral prostates. Mice were divided into two groups with those running $>5 \mathrm{~km} /$ day vs. those running $<5 \mathrm{~km} /$ day. Fisher's Exact was run with significance set at $P \leq 0.05$. None of the dorsal prostates from the mice running $>5 \mathrm{~km} /$ day displayed HG PIN (* statistically significant at $P=0.05$ ). There was a trend for less HG PIN in the ventral prostate of mice that ran $>5 \mathrm{~km} /$ day but this was not statistically significant. 


\section{TABLE I}

Descriptive Running Wheel Data

\begin{tabular}{|c|c|c|c|}
\hline Mouse number & Distance: $\mathrm{km} / \mathrm{day}$, average \pm SEM & Speed: $\mathrm{km} / \mathrm{hr}$, average \pm SEM & Time hr/day, average \\
\hline R01 & $3.43 \pm 0.28$ & $0.74 \pm 0.03$ & 4.7 \\
\hline R02 & $3.03 \pm 0.28$ & $0.63 \pm 0.03$ & 4.7 \\
\hline R03 & $4.71 \pm 0.33$ & $0.89 \pm 0.02$ & 4.9 \\
\hline R04 & $5.50 \pm 0.33$ & $0.75 \pm 0.02$ & 7.4 \\
\hline R05 & $4.16 \pm 0.22$ & $0.82 \pm 0.04$ & 5 \\
\hline R06 & $3.66 \pm 0.32$ & $0.82 \pm 0.04$ & 4.2 \\
\hline R07 & $5.61 \pm 0.31$ & $0.92 \pm 0.02$ & 6.4 \\
\hline R08 & $7.72 \pm 0.41$ & $0.95 \pm 0.03$ & 7.8 \\
\hline R09 & $5.96 \pm 0.31$ & $0.85 \pm 0.03$ & 6.8 \\
\hline $\mathrm{R} 10$ & $5.44 \pm 0.28$ & $0.86 \pm 0.02$ & 6.1 \\
\hline R11 & $4.46 \pm 0.28$ & $0.68 \pm 0.02$ & 6.2 \\
\hline $\mathrm{R} 12$ & $3.05 \pm 0.26$ & $0.70 \pm 0.03$ & 4.3 \\
\hline $\mathrm{R} 13$ & $3.73 \pm 0.28$ & $0.60 \pm 0.02$ & 6 \\
\hline R14 & $2.72 \pm 0.20$ & $0.87 \pm 0.03$ & 3 \\
\hline R15 & $3.90 \pm 0.33$ & $0.65 \pm 0.02$ & 5.4 \\
\hline R16 & $5.25 \pm 0.28$ & $0.92 \pm 0.03$ & 5.5 \\
\hline R17 & $1.30 \pm 0.20$ & $0.80 \pm 0.05$ & 1.8 \\
\hline R18 & $1.26 \pm 0.18$ & $0.38 \pm 0.02$ & 2.9 \\
\hline R19 & $2.63 \pm 0.21$ & $0.54 \pm 0.02$ & 4.4 \\
\hline $\mathrm{R} 20$ & $4.23 \pm 0.32$ & $0.69 \pm 0.03$ & 5.7 \\
\hline Average & $4.03 \pm 0.39 \mathrm{~km} / \mathrm{day}$ & $0.72 \pm 0.05 \mathrm{~km} / \mathrm{hr}$ & $5.2 \mathrm{hr} /$ day \\
\hline
\end{tabular}

Prostate. Author manuscript; available in PMC 2010 November 4. 